\title{
Manuel Cruz, Adiós, historia, adiós. El abandono del pasado en el mundo actual. Oviedo: Nobel, 2012, 252 págs.
}

"La historia no ha terminado, somos nosotros quienes la hemos abandonado". Con esta rotunda sentencia se abre Adiós, historia, adiós, la última obra del filósofo Manuel Cruz, ganadora del Premio Internacional de Ensayo Jovellanos 2012. Al pasar sus páginas, pronto se advierte que no es un libro fácil, porque no es un libro cualquiera. Más bien parece una summa de los motivos principales que han recorrido la trayectoria del autor desde su temprana Narratividad: la nueva síntesis, de 1986, hasta Las malas pasadas del pasado, que en 2005 mereció el Premio Anagrama de Ensayo. Los asuntos que ahí se tratan, tales como la memoria, la historia, la identidad o la responsabilidad, aparecen ahora revisados a la luz de los desafíos del presente. Aunque hacer mención a la luz quizá sea ya decir demasiado, puesto que el panorama que dibuja nuestro tiempo se antoja, a juicio del autor, repleto de sombras. Ahora bien, la noche es más oscura justo antes del amanecer. De modo que, por si acaso, mejor no renunciar todavía a la urgente tarea de pensar.

¿Qué nos ofrece Manuel Cruz para ello? Más cosas de las que cabe reseñar adecuadamente, por lo que se hace necesario seleccionar. Empezaré, pues, por un punto sustantivo de su diagnosis que puede enunciarse así: la hodierna incapacidad de establecer nuevas fronteras en el tiempo. En efecto, todo acto rememorativo tiene como fin tal delimitación, o dicho de otra manera, la fundación de nuestro pasado. Así sucede, por ejemplo, cuando nos reclamamos herederos de la revolución francesa, o de la segunda república española, o del consenso constitucional de la transición democrática. Al hacerlo, transformamos esos hechos en acontecimientos, esto es, en puntos de referencia para nosotros y para las generaciones futuras que no solo inauguran el futuro sino que, a fortiori, instituyen el pasado.

Porque el pasado no es un tiempo muerto, al que quepa aproximarse con una curiosidad entomológica, sino una materia prima a la que el trabajo de la memoria puede dar vida y destino. Y, sin embargo, hoy esta tarea de darnos mapas del tiempo más allá de los meteorológicos, claro está- emite signos de agotamiento. Quizá sea por el miedo al cambio, por esa sensación de que, si todo sigue como antes, estaremos a salvo de ignotos sobresaltos y catástrofes. O quizá sea por el rechazo a la tradición que impregna nuestras sociedades, y que se desdobla en una exaltación de lo nuevo permanente, pero vacía.

En tales circunstancias, conviene recordar la necesidad de desprendernos de una imagen homogénea y lineal del tiempo. O, más concretamente, de la filosofía progresista de la historia concebida entre los siglos dieciocho y diecinueve. Relacionarnos productivamente con el pasado exige hoy repensar el tiempo histórico tal como lo ha concebido la modernidad, es decir, como un sustantivo colectivo singular cuya representación es una sucesión geométrica de instantes iguales y sin duración. En este caso, tenemos un tiempo con el que deben sincronizarse todos los relojes, sin margen para las discordancias, los contratiempos o las heterocronías, que entiende que el presente es absolutamente autosuficiente.

Pero toda una tradición de pensamiento nos alerta de la falsedad de tal pretensión. La 'contemporaneidad de lo no contemporáneo' de Ernst Bloch, las 'temporalidades 
diferenciales' de Louis Althusser o los 'estratos de tiempo' de Reinhart Koselleck, por citar solo algunos ejemplos, llaman la atención sobre las impurezas del tiempo, las supervivencias y los anacronismos. Y, ciertamente, pensadores como Agamben o Derrida nos han enseñado las virtudes de lo anacrónico para pensar lo contemporáneo, para lo cual se requiere romper el hechizo de un presente sumido en la ensoñación narcisista del fin de la historia, y también, frente a las veleidades omnímodas de lo actual, contraponer firmemente la "no contemporaneidad a sí del presente vivo". El presente, y nosotros que lo habitamos, estamos atravesados por elementos que vienen del pasado y por otros que están por venir. No deberíamos darles la espalda.

Tampoco tendríamos que olvidarnos de las impurezas y las discordancias del tiempo cuando de lo que se trata es de pensar nuestra identidad. En la actualidad se soslaya con demasiada frecuencia el hecho de que lo que somos, cada uno y cualquier nosotros en el que nos integremos, es fruto de la interacción y la recíproca eficacia de instancias múltiples y diversas. Por eso mismo, "por más compacta, coherente e inmutable que en cualquier momento de la historia pueda haberse mostrado una determinada configuración de la subjetividad, una mirada diacrónica suficientemente abarcadora nos aboca a cuestionar semejante apariencia" (p. 140). Las implicaciones sociales de esta constatación saltan a la vista. Si una comunidad no es capaz de cribar su propio pasado, de someterlo a crítica e incluso dar espacio a la amnesia creativa, al final el tiempo será un peso imposible de sobrellevar. Del mismo modo, si una persona es incapaz de elaborar la memoria de sus agravios, acabará presa de una victimización paralizante o resentida.

Lo cual nos lleva a otro asunto que la obra de Cruz aborda y que conviene destacar. Se trata de la tensión entre la unicidad de todo acontecimiento, la singularidad de su ocurrencia, y la repetición ínsita en su recuerdo y su narración. Observemos la cuestión. La historia y la biografía comparten la ambición de integrar en una trama los sucesos que van ocurriendo. Así se compone lo que Paul Ricœur ha llamado 'identidad narrativa'. Ahora bien, los acontecimientos, por definición, son aquellos momentos que rompen esa trama, pues poseen un carácter explosivo e imprevisto. Tanto es así que un acontecimiento nunca puede deducirse de sus causas. Es él mismo el que ilumina retrospectivamente el pasado que ha venido a subvertir. Dicho esto, la tendencia habitual es intentar recomponer la trama para integrar en ella el acontecimiento y, de esta manera, comprenderlo.

El problema es que así lo único que se consigue es esconder, pero no anular, la potencia de sus efectos. La alternativa que propone esta obra es estar a la altura del acontecimiento y asumir la determinación de reconocerle el carácter rupturista e innovador. Frente a la evasión que supone arrumbar aquello que nos altera, o la fosilización en que deparan la mayor parte de las formas de conmemoración, es preciso aceptar la necesidad de reescribir permanentemente la historia para dar cuenta de los efectos de los acontecimientos. Derrida propone hacerlo a través de la iterabilidad, esa forma de repetición que no consiste en reinscribir un hecho en su contexto sino en liberarlo de él, cambiando a cada paso su significado, y rechazando toda fuente pura, unívoca y permanente de sentido.

\footnotetext{
1 Jacques Derrida, Espectros de Marx. El estado de la deuda, el trabajo del duelo y la nueva Internacional (Madrid: Trotta, 1995), 13.
} 
Aquí se dibuja una primera prescripción para quienes se ocupan del estudio del pasado: "la historia debe sobresaltar" (p. 188). Cuando no se lo propone es de temer que lo que está produciendo no es conocimiento sino solo reconocimiento, en un gesto que hace del pasado un espejo mágico que, como en el cuento, solo nos dice lo que queremos oír. Por el contrario, una buena historia no concibe el pasado como algo determinado de antemano ni como algo determinante para nosotros. Antes bien, revela la amplitud del campo de lo posible y la contingencia de cuanto ha terminado imponiéndose. Además, no solo recupera los hechos luminosos, sino también los oscuros, y constituye una instancia crítica con la que confrontar nuestras acciones en el presente y nuestros proyectos para el futuro, subrayando así el valor de nuestra responsabilidad. En suma, una buena historia "muestra la necesidad de articular la consciencia histórica con la dimensión política" (p. 165).

¿Cómo puede hacerlo? Haciendo valer lo que Alessandro Ferrara ha llamado 'la fuerza del ejemplo', una fuerza que tiene que trascender el antiguo tópico de la historia como maestra de vida y, a la vez, resistir al 'vértigo de la analogía' del que ha hablado Jacques Bouveresse. Ciertos acontecimientos tienen un carácter ejemplar, y los ejemplos, más que los enunciados generales y abstractos, ejercen sobre nosotros una particular atracción por dos motivos: por la excepcional congruencia que exhiben entre el orden de la realidad en la que actúan y el orden de la normatividad a la que responden, y porque inscriben las emociones en el corazón de la razón. Además, el ejemplo que se produce en un contexto local puede tener validez universal, toda vez que "la fuerza persuasiva del ejemplo, a diferencia de la fuerza persuasiva de una ley o un principio, es enteramente autorreferencial" y su normatividad no requiere traducción. ${ }^{2}$ Porque, en efecto, lo que se traslada no es tal o cual acción concreta y la necesidad de repetirla, sino la congruencia entre la acción y su regla, entre el acontecimiento y la imaginación. Disponemos así de la clave para acceder a un 'universalismo ejemplar'. Pero esto es todo. Para que el ejemplo no sufra los estragos del tiempo y pierda por consiguiente su eficacia, es necesario introducir en nuestra lectura del pasado la perspectiva de una 'hermenéutica del ejemplo'.

Y, sin embargo, ¿qué posibilidades tiene la historia de ejercer fructíferamente su labor? El libro de Manuel Cruz se cierra con un pronóstico inquietante. Los antiguos podían sentir que su tiempo estaba en decadencia, pero mantenían alguna confianza en el pasado como fuente de lecciones para guiar su acción. Los modernos tampoco se sentían cómodos con su tiempo, pero confiaban en su capacidad de transformarlo para alcanzar un futuro distinto y mejor. ¿Y nosotros? La obra comparte la tesis de François Hartog sobre el carácter devorador, monstruoso, de nuestro presente, que igual se sirve para saciar su apetito de la recuperación calculada del pasado por medio de la conmemoración —en un movimiento con el que, en realidad, el presente se conmemora a sí mismo y se concibe como ya histórico-, como de la proyección controlada del futuro, al que arrebata toda dimensión utópica para convertirlo en el erial del eterno retorno de lo mismo. Pero aún peor es que, en medio de este paisaje desolado, aparece un presente tan sobrecrecido, con tantas posibilidades efectivamente realizadas, que él mismo resulta incomprensible e inverosímil.

\footnotetext{
2 Alessandro Ferrara, La fuerza del ejemplo. Exploraciones del paradigma del juicio (Barcelona: Gedisa, 2008), 43 .
} 
Las novedades cualitativas que esperábamos del futuro se sustituyen ahora por las exponenciales novedades cuantitativas del presente. El futuro ya no es lo que era, y desde luego ya no excita como solía nuestra imaginación. De hecho, hoy las únicas proyecciones que se hacen sin parar tienen un sesgo claramente naturalista: marcha de la economía, evolución del clima, curva de la población, volumen de alimentos, reservas energéticas, alcance de las enfermedades, etcétera. En cambio, apenas se habla de pronósticos de carácter voluntarista. ¿Qué se ha hecho de aquello de transformar este mundo para hacerlo más justo, más equitativo, más humano, y menos violento, menos codicioso, menos voraz? Esto agrava todavía más el supuesto de que el futuro será la mera repetición de lo que ya hay. Hoy asumimos que el mundo puede cambiar, pero que si lo hace será hacia peor, y desde luego no gracias al resultado de nuestra acción. La contingencia ya no se abre al mundo de la liberadora posibilidad, sino al del inseguro azar. El porvenir se ha vuelto una amenaza.

Arendt, Benjamin, Koselleck o Ricœur imaginaron, cada uno a su manera, que la reconsideración del pasado ofrecería la posibilidad de mantener una relación crítica con el presente que contribuyera a mejorarlo. Para ellos, el pasado tenía que actuar como germinador de las semillas del tiempo, como revelador de las potencias que el presente es capaz de actualizar. Pero la naturalización que caracteriza a nuestro tiempo no solo nos deja al albur de unas transformaciones que escapan a nuestro control. También parece dejarnos en la intemperie teórica, pues nos es ya muy difícil encontrar acomodo a las pretensiones de todos los pensadores que hasta ahora alumbraban nuestro camino. Hoy, aquel sujeto de la historia que, de la mano de Hegel, estaba destinado a dominar la naturaleza y a dirigir, aun sometido a la astucia de la razón, el rumbo de los acontecimientos ha perdido su rostro. Hoy siempre son otros - por ejemplo, los tan traídos mercados - quienes llevan las riendas del mundo. Pero parece que lo que ellos hacen es destruir la naturaleza y conducir la historia de nuestras sociedades hacia la implosión.

Y, con todo, algo hay que hacer, porque si nos desprendemos de nuestro pasado, "si nosotros nos declaramos otros, radicalmente distintos a quienes nos precedieron, en nombre de lo mismo nada de nosotros ni de lo que hagamos tiene la menor posibilidad de trascendernos y ser recogido como propio por quienes residan en el porvenir" (pp. 248-9). Este libro, a pesar de su conclusión, contiene numerosos elementos para evitar una resignación a la que no debiéramos ceder.

Porque si eso hacemos, nadie hablará de nosotros cuando hayamos muerto.

Vladimir López Alcañiz

cosmopolis1789@hotmail.com

Universitat Autònoma de Barcelona

Fecha de recepción: 10 de noviembre de 2012

Fecha de aceptación: 23 de noviembre de 2012

Publicado: 31 de diciembre de 2012 
Historiografías, 4 (Julio-Diciembre, 2012): pp.122-126.

Para citar: Vladimir López Alcañiz, "Manuel Cruz, Adiós, historia, adiós. El abandono del pasado en el mundo actual. Oviedo: Nobel, 2012, 252 págs.”, Historiografías, 4 (enero-junio, 2012): pp. 122-126, http://www.unizar.es/historiografias/historiografias/numeros/4/lopez.pdf 